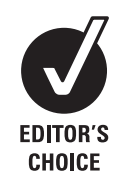

${ }^{1} \mathrm{CICH}$, Institute of Child Health, UCL, London, UK 2Insitute of Global Health, UCL, London, UK

${ }^{3}$ Psychosocial Support and Children's Rights Resource Centre, Manila, Philippines

\section{Correspondence to}

Therese M Hesketh, Institute of Child Health, UCL, CICH, 30 Guilford St, London WC1 N1EH, UK;

t.hesketh@ich.ucl.ac.uk

Received 2 February 2012 Accepted 1 May 2012 Published Online First 9 June 2012

\title{
The psychosocial impact of child domestic work: a study from India and the Philippines
}

\author{
Therese M Hesketh, ${ }^{1}$ Jennie Gamlin, ${ }^{2}$ Michelle Ong, ${ }^{3}$ Agnes Zeneida V Camacho ${ }^{3}$
}

\begin{abstract}
The aim of the study was to explore the effects of domestic employment on the well-being of child domestic workers (CDWs) in India and the Philippines. A questionnaire was administered to $700 \mathrm{CDWs}$ and 700 school-attending controls in the two countries. In India, $36 \%$ of CDWs started work before age $12,48 \%$ worked because of poverty or to repay loans, $46 \%$ worked $>10 \mathrm{~h}$ per day, and $31 \%$ were physically punished by employers. Filipino CDWs were mainly migrants from rural areas, $47 \%$ were working to continue their studies and $87 \%$ were attending school, compared with $35 \%$ of Indians. In India, $67 \%$ of CDWs and $25 \%$ of controls scored in the lowest tertile $(p<0.001)$ compared with $36 \%$ and $30 \%$, respectively, in the Philippines $(p=02)$. Key significant correlates of low psychosocial scores were non-attendance at school, long working hours, physical punishment, limited support networks and poor health. This study shows that it is not domestic work that is intrinsically harmful, but rather the circumstances and conditions of work, which could be improved through pragmatic regulatory measures.
\end{abstract}

\section{INTRODUCTION}

Child domestic workers (CDWs) are defined as children under the age of 18 who work in an employer's home performing household duties such as cooking, cleaning, child care and care of older people. While accurate figures for CDWs are impossible to obtain because of its clandestine nature, it is estimated that around $10 \%$ of all child workers are in domestic service, with girls comprising $90 \%$ of the total. As many as 10 million CDWs are employed worldwide with estimates of up to 3 million in India and 1 million in the Philippines. ${ }^{1}$

Child domestic work is often accepted in the societies where it exists, and it is often viewed as a safe form of employment. ${ }^{2}$ But CDWs may be especially prone to exploitation and abuse due to the invisibility and inaccessibility of the work setting. ${ }^{3}$ Largely because of this, there have been calls for child domestic work to be classified as a 'worst form of child labour', as defined in ILO Convention 182. ${ }^{5}$ This would put domestic work among the forms of child labour which are a "priority to eliminate without delay".

One of the factors influencing the debate around classification as a 'worst form of child labour' is the potential psychosocial impact of work on children. To date the focus of research has primarily been on working conditions and environmental hazards. ${ }^{6}$ Research into psychosocial issues has been limited, and in terms of domestic work has tended to focus on the extremes. ${ }^{3} 78$ While this provides important context concerning some of the most vulnerable children, it does not reflect the experience of the overwhelming majority of CDWs. Moreover, there is no research that specifically explores the effects of work and living conditions on the psychosocial well-being of CDWs.

The aims of this study, therefore, were to provide a more generalisable understanding of the effects of domestic employment on children's psychosocial well-being, and to explore specific determinants of poor psychosocial status, with a view to informing policy in this area.

\section{METHODS}

The study consisted of a cross-sectional survey of CDWs and school-attending community controls carried out under the auspices of the NGO Anti-Slavery International (ASI), and in collaboration with two local partner organisations: The National Domestic Workers Movement in India, and Visayan Forum in the Philippines.

A questionnaire was developed for the study building on qualitative research previously conducted by ASI, ${ }^{2} 9$ research into the psychosocial effects of child labour by Woodhead ${ }^{10}$ and a study exploring appropriate tools for psychosocial measurements in child labour. ${ }^{11}$ Woodhead's work identified potential vulnerability and protective factors which could affect a child's psychosocial well-being in the work setting. These factors include: consistent settings, secure relationships, peer support and solidarity, physical environment and daily schedule, and opportunities for participation in school and other community activities. The questionnaire incorporated questions about these areas. In addition, we developed a scoring system for the measurement of psychosocial well-being, drawing on Woodhead's framework for child labour, ${ }^{12}$ which identifies the following factors as contributing to psychosocial well-being: sense of personal competence, social integration, personal identity and valuation, and emotional and somatic expressions of well-being. Using this framework, we drew up a series of 20 questions (with answers Yes/Don't know/No, scoring 2, 1 and 0, respectively, with some questions reverse-marked) to measure psychosocial well-being through the development of a unitary score. The maximum theoretical score is 40 and the minimum is 0 . The questionnaire was translated into local languages using the translation-back translation method for accuracy and was extensively piloted and pretested in India and the Philippines before the final version was agreed. 
Table 1 Sociodemographic characteristics of CDWs and controls ( $\mathrm{n} \%$ )

\begin{tabular}{|c|c|c|c|c|c|}
\hline & \multicolumn{2}{|c|}{ India } & \multicolumn{2}{|c|}{ Philippines } \\
\hline & & CDWs & Controls & CDWs & Controls \\
\hline \multirow[t]{2}{*}{ Gender } & Male & 55 (11) & $55(11)$ & $25(13)$ & $90(45)$ \\
\hline & Female & $445(89)$ & $445(89)$ & $174(87)$ & $110(55)$ \\
\hline \multirow[t]{3}{*}{ Age } & $<12$ years & $10(2)$ & $25(5)$ & $2(1)$ & $2(1)$ \\
\hline & $12-15$ years & $356(71)$ & $388(77)$ & $71(36)$ & $132(66)$ \\
\hline & $16-18$ years & $134(27)$ & $87(17)$ & $124(62)$ & $66(33)$ \\
\hline \multirow[t]{2}{*}{ Migration status } & Family in area & $415(83)$ & $500(100)$ & $65(33)$ & $154(79)$ \\
\hline & Born in area & $335(68)$ & $453(91)$ & $63(33)$ & $54(27)$ \\
\hline \multirow[t]{5}{*}{ Home situation } & Parents live together & $332(66)$ & $348(69)$ & $136(68)$ & $133(66)$ \\
\hline & Parents separated & $65(13)$ & $42(8.9)$ & $25(12)$ & $30(15)$ \\
\hline & Parents apart for work & $44(8.8)$ & $46(9.2)$ & $3(1.5)$ & $9(4.5)$ \\
\hline & One parent dead & $50(10)$ & $56(11)$ & $24(12)$ & $20(10)$ \\
\hline & Both parents dead & $4(0.8)$ & $2(0.4)$ & 0 & $1(0.5)$ \\
\hline
\end{tabular}

CDW, child domestic worker.

Data were gathered between April and October 2009 by specifically trained researchers working through the local partner organisations. These organisations selected the locations for the research. In India these were six states: Tamil Nadu, Kerala, Maharashtra, Andhra Pradesh, Uttar Pradesh and Bihar, and in the Philippines six cities: Manila, Batangas, Bocolod, Cebu, Davao, Dumaguete and Iloilo. The aim was to achieve a sample size of 200 CDWs and 200 controls in each group. Around $60 \%$ of the CDWs in each country sample were in contact with the local NGO. Others were identified through snowballing techniques. Sampling was thus of necessity opportunistic, although an attempt was made to reach younger CDWs (under 14s), boys and live-in CDWs. Control group children were all attending schools in the same area as the CDW population and the aim was to achieve matching by age and sex. School principals were asked to participate by representatives of the partner organisation. The questionnaire could be self-administered or conducted as a one-to-one interview. Control group children mostly used the self-administered method, while the majority of CDWs underwent face-toface interviews at the family home, the facilities of the partner organisation, or in the employer's home when the employer was absent. Considerable care was taken to ensure that each child understood what the process of the research involved before they consented to participate. Confidentiality and anonymity were assured. No child refused to be interviewed in the Philippines, but 15 CDWs did so in India. The very high response rate given the sensitivity of the subject matter is certainly attributable to the experience and skills of the staff from the partner organisations in relating to these children.

Ethics approval was obtained locally through partner organisations and from the UCL Ethics Committee.

\section{Analysis}

The psychosocial score for each child was summated and then dichotomised to low and high, lowest tertile and upper two tertiles. Correlates of low scores were then analysed using bivariate analysis. Analysis was carried out using SPSS V.18

\section{RESULTS}

\section{Sociodemographic characteristics}

Completed questionnaires were obtained from 200 CDWs and 200 controls in the Philippines and from 500 CDWs and 500 controls in India. The Indian partner organisation decided on the larger sample for their own purposes and results for all 1000 are reported here. As shown in table 1, there are some notable differences in the sociodemographic profile between CDWs in the Philippines and those in India. Filipino CDWs are older, and are more likely to have migrated from elsewhere (rural areas) and to have no nearby close family support.

\section{Living and working conditions}

Indian CDWs start work younger (over one-third before age 12) and most are forced into domestic work through poverty (table 2). Although only $12 \%$ live with their employer, they work very long hours and only $8.6 \%$ have a day off. In the Philippines, the CDWs claim to be working mainly to continue their studies and 54\% live-in with the employer. They work shorter hours overall than the Indian CDWs, and are more likely to get a day off. Nearly all Filipinos (87\%) attend school, and most think they are doing well in school. In contrast, $27 \%$ of Indians attend school with a third of these feeling they are doing well. Punishment appears to be much harsher for Indian CDWs with one-third being physically beaten or deprived of food for misdemeanours, compared to just $1 \%$ of the Filipino children. There is a marked contrast in attitudes to work in the two countries. The overwhelming majority of the Filipino CDWs claim to like their work and to gain pride from it, in contrast to low proportions in India. In addition, Filipino CDWs seem to have stronger levels of social support both from other CDWs and from adults (table 3), findings confirmed in the psychosocial component below.

\section{Psychosocial health}

Table 4 shows the percentage of positive responses to the psychosocial questions together with the total scores. In India the CDWs score lower than controls, while there is no significant difference in the scores for CDWs and controls in the Philippines. Dichotomising the total score shows that $67 \%$ of CDWs in India and $36 \%$ in the Philippines could be classified as vulnerable, compared to $25 \%$ and $30 \%$ in the control groups, respectively. Key correlates of low psychosocial score in CDWs for each country are shown in table 5. Consistent correlates across the two countries are non-attendance at school, long working hours, poor self-reported health and lack of support through peers or adults, or through attendance at a community centre. In India, in addition, young age and not 
Table 2 Living and working conditions of CDWs

\begin{tabular}{|c|c|c|c|c|c|}
\hline & & \multicolumn{2}{|c|}{ India $(n=500)$} & \multicolumn{2}{|c|}{ Philippines $(n=200)$} \\
\hline & & n (95\% CI) & $\%$ & n (95\% CI) & $\%$ \\
\hline \multirow[t]{3}{*}{ Age started work } & $9-11$ years & $180 \pm 20$ & 36 & $20 \pm 8$ & 10 \\
\hline & $12-14$ years & $260 \pm 23$ & 52 & $103 \pm 14$ & 56 \\
\hline & $15-17$ years & $60 \pm 15$ & 12 & $62 \pm 12$ & 31 \\
\hline \multirow{5}{*}{$\begin{array}{l}\text { Reason for going into child } \\
\text { domestic work }\end{array}$} & Poverty & $195 \pm 20$ & 39 & $28 \pm 10$ & 14 \\
\hline & To continue studies & $75 \pm 15$ & 15 & $94 \pm 14$ & 47 \\
\hline & Parents decided & $110 \pm 19$ & 22 & $54 \pm 12$ & 27 \\
\hline & Loan repayment & $42 \pm 14$ & 8.5 & 0 & \\
\hline & Not known & $75 \pm 15$ & 15 & $24 \pm 9$ & 12 \\
\hline \multirow[t]{3}{*}{ Who do you live with? } & Own family & $418 \pm 15$ & 84 & $59 \pm 13$ & 30 \\
\hline & Employer & $61 \pm 11$ & 12 & $106 \pm 14$ & 54 \\
\hline & Others & 0 & 0 & $31 \pm 10$ & 15 \\
\hline Day off & Yes & $43 \pm 11$ & 8.6 & $10 \pm 14$ & 51 \\
\hline \multirow[t]{4}{*}{ Hours of work/day } & $<6$ & $8 \pm 5$ & 1.6 & $51 \pm 12$ & 26 \\
\hline & $7-9$ & $270 \pm 21$ & 54 & $39 \pm 11$ & 20 \\
\hline & $10-12$ & $215 \pm 16$ & 43 & $31 \pm 10$ & 15 \\
\hline & $>12$ & $15 \pm 6$ & 3 & $39 \pm 12$ & 20 \\
\hline \multirow[t]{2}{*}{ Paid for work done } & Monetary & 500 & 100 & $115 \pm 14$ & 57 \\
\hline & Non-monetary & 0 & 0 & $20 \pm 8$ & 10 \\
\hline Currently attending school & Yes & $175 \pm 18$ & 35 & $172 \pm 10$ & 87 \\
\hline \multirow{7}{*}{$\begin{array}{l}\text { What does your employer do if } \\
\text { you do something wrong? }\end{array}$} & Nothing & $14 \pm 7$ & 3 & $20 \pm 9$ & 10 \\
\hline & Scolds me & $254 \pm 22$ & 51 & $36 \pm 10$ & 18 \\
\hline & Teaches/corrects me & $58 \pm 14$ & 12 & $121 \pm 14$ & 60 \\
\hline & Beats me & $118 \pm 19$ & 24 & $2 \pm 1$ & 1 \\
\hline & Deprived of food & $35 \pm 11$ & 7 & 0 & 0 \\
\hline & Reduced salary & $21 \pm 9$ & 4.2 & 0 & 0 \\
\hline & Other & 0 & 0 & $4 \pm 3$ & 2 \\
\hline
\end{tabular}

CDW, child domestic worker.

Table 3 Attitudes to work and social support

\begin{tabular}{|c|c|c|c|c|c|}
\hline & & \multicolumn{2}{|c|}{ India $(n=500)$} & \multicolumn{2}{|c|}{ Philippines (n=200) } \\
\hline & & n (95\% CI) & $\%$ & n (95\% CI) & $\%$ \\
\hline \multirow[t]{3}{*}{ Do you like working? } & Yes & $134 \pm 19$ & 27 & $152 \pm 12$ & 76 \\
\hline & No & $261 \pm 20$ & 52 & $17 \pm 8$ & 9 \\
\hline & Don't know & $105 \pm 18$ & 21 & $19 \pm 9$ & 10 \\
\hline \multirow[t]{3}{*}{ Are you proud of your work? } & Yes & $148 \pm 20$ & 30 & $165 \pm 10$ & 83 \\
\hline & No & $255 \pm 22$ & 51 & $11 \pm 6$ & 6 \\
\hline & Don't know & $97 \pm 17$ & 19 & $6 \pm 4$ & 3 \\
\hline \multirow[t]{2}{*}{ Self-reported health } & Poor/fair & $145 \pm 16$ & 29 & $36 \pm 10$ & 18 \\
\hline & Good/very good & $355 \pm 22$ & 71 & $164 \pm 12$ & 82 \\
\hline \multirow[t]{3}{*}{ Able to visit family } & Yes & $144 \pm 19$ & 29 & $136 \pm 12$ & 68 \\
\hline & No & $5 \pm 4$ & 1 & $52 \pm 10$ & 26 \\
\hline & Not applicable & $351 \pm 21$ & 70 & $12 \pm 5$ & 6 \\
\hline Friends with other CDWs & Yes & $252 \pm 22$ & 50 & $128 \pm 11$ & 64 \\
\hline Feels supported by adults & Yes & $158 \pm 20$ & 31 & $140 \pm 13$ & 70 \\
\hline \multirow[t]{3}{*}{ Attends community centre* } & Often & $275 \pm 22$ & 55 & $120 \pm 12$ & 60 \\
\hline & Rarely & $45 \pm 13$ & 9 & $6 \pm 4$ & 3 \\
\hline & Never & $175 \pm 21$ & 35 & $74 \pm 11$ & 37 \\
\hline
\end{tabular}

*These are predominantly the community support groups provided by the local partner organisations. CDW, child domestic worker.

having a day off, living-in and non-verbal punishment (beating, withholding food) were also significantly correlated with a low psychosocial score.

\section{DISCUSSION}

This is the first study to our knowledge which assesses the effects of domestic work on the psychosocial well-being of children. It has a number of limitations. First, sampling is biased by the clandestine nature of the worst forms of this work. Although we attempted to reach children in the most difficult situations, we are aware that this population is under-represented. Second, the psychosocial scoring system was developed for this study, and it was impossible to conduct formal validation. However, we believe that internal comparisons are 
Table 4 Responses to psychosocial questions: percentage of positive responses by group and country

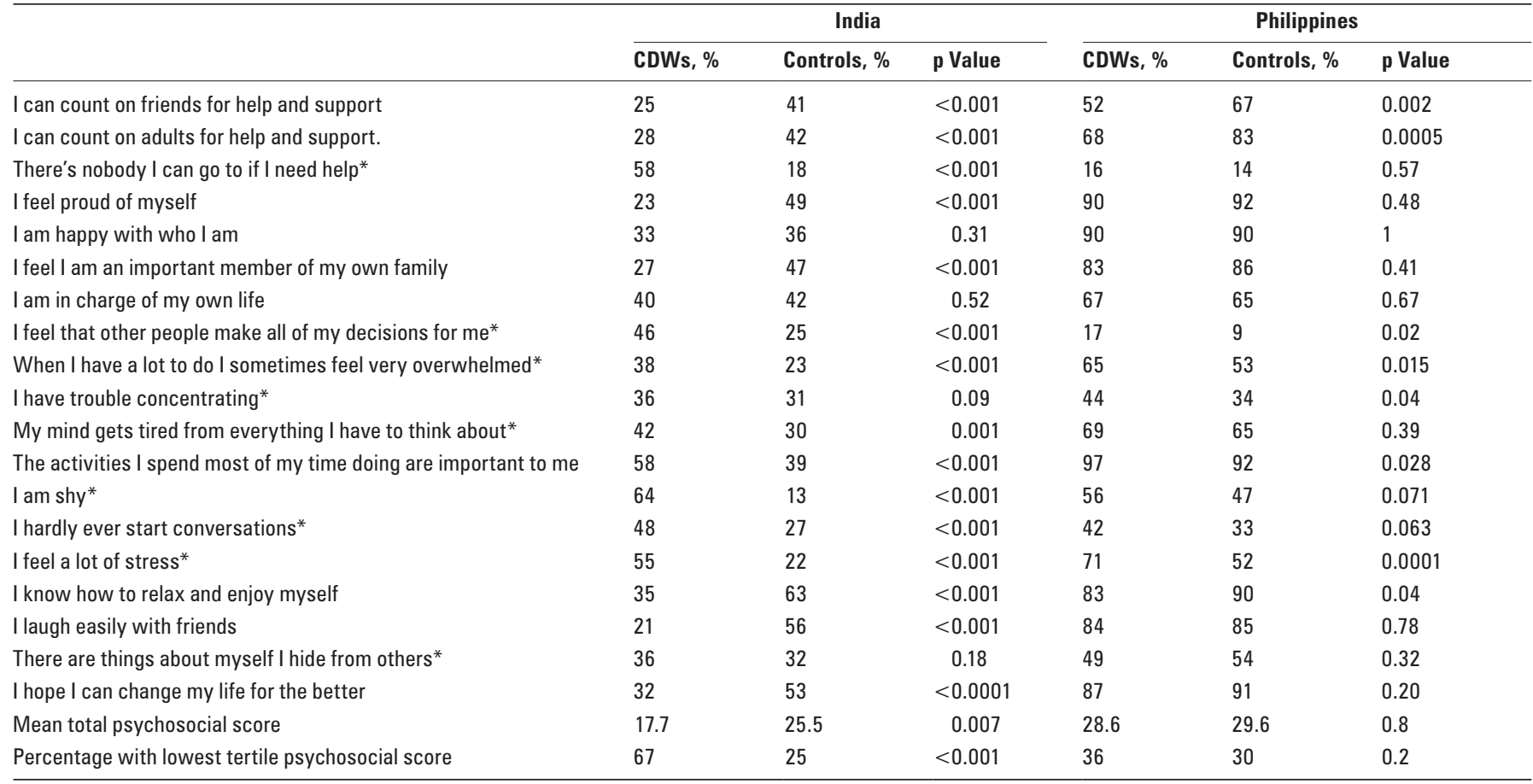

${ }^{*}$ Reversed for summating total score.

CDW, child domestic worker.

useful and informative, especially regarding the responses to individual items as shown in table 4 . In addition, we included some repeat questions, worded slightly differently, and these demonstrated good internal validity. The dichotomisation of scores to create a more vulnerable group is essentially arbitrary, but it was agreed among the researchers that children in the lowest tertile were likely to be highly vulnerable. Third, the quantitative approach may not encourage interviewees to raise specific concerns or share confidences and may lead to evasive or selective responses. But in the context and given the necessity to use local researchers, we deemed a quantitative approach more appropriate.

Despite the limitations, the findings in these two countries shed light on the diversity of expectations, conditions and outcomes encompassed in the term child domestic work. In India children generally enter domestic service young, live with their own families, are at risk of physical abuse, seldom attend school and have poor psychosocial outcomes, in the form of low self-esteem, stress and feelings of incompetence. In contrast, in the Philippines CDWs are mostly migrants, live with employers, combine education with work, appear to have a good relationship with employers and are proud of what they do. This results in good psychosocial outcomes, equivalent to those of school attenders. For many families in India child domestic work is a survival strategy, and $8.5 \%$ of CDWs were paying off family debts. In the Philippines domestic work is viewed more as a chance to earn money to attend better schools, providing an opportunity to move up the social ladder. This positive view coincides with earlier research from the Philippines which concluded that in poor families domestic work is seen as a highly pragmatic approach to continuing education. ${ }^{13} 14$

The bivariate analysis shows some strong and consistent risk factors for psychosocial vulnerability in the two countries. School attendance has highly beneficial effects. CDWs who are not in education are approximately three times more likely to be in the lowest psychosocial tertile in both India and the Philippines. The relationships between education and entry into domestic work are complex. Some children enter work as a means of continuing their studies, while other leave school in order to work. Importantly, attending school makes children visible, providing a form of protection and social capital in the form of friendship, social activities and supportive adults. Education also increases options, gives hope for the future, and offers a potential escape from long term domestic drudgery. ${ }^{15} 16$ Linked to this is the strong protective factor of social capital per se, which in this context consists of relationships with other CDWs, adult support, and attending a community group, illustrating the importance of support networks for well-being. Adult support and relationships with employers were especially important in the Philippines where the majority of CDWs are migrants, whose close family networks are out of reach, and where most lived-in. The potential vulnerability of child migrant workers has been highlighted elsewhere, ${ }^{10} 13$ and this emphasises the importance of increasing the awareness of employers. As Bourdillon et al point out, "It may not be the work per se which defines the boundary between harmful and benign work for children, but rather whether the children and their interests are respected by the controlling adults". ${ }^{4}$

Although not surprisingly the overwhelming majority of CDWs reported good health (children in poor health will not continue to work, demonstrating a clear healthy worker effect), there was an association between poor or fair selfreported health and psychosocial well-being. While poor health of course impairs general well-being, it may be that these children are manifesting psychosomatic symptoms. An additional question asking about specific symptoms showed that most were headache and abdominal pain, classic psychosomatic symptoms.

Some psychosocial correlates differed between India and the Philippines. Younger children had lower psychosocial scores in 
Table 5 Correlates of psychosocial vulnerability of CDWs (score in the lowest tertile)

\begin{tabular}{|c|c|c|c|c|c|c|c|}
\hline & & & India $(n=280)$ & & & Philippines $(n=73$ & \\
\hline & & $\mathrm{n}(\%)$ & OR (95\% Cl) & p Value & n (\%) & OR (95\% CI) & $\mathrm{p}$ Value \\
\hline Age, years & $\leq 15$ & $210(59)$ & $1.2(1.05$ to 1.3$)$ & 0.02 & $28(38)$ & $1.0(0.7$ to 1.3$)$ & 0.8 \\
\hline & $>15$ & $70(51)$ & & & $45(36)$ & & \\
\hline Living in & Yes & $46(75)$ & $1.4(1.2$ to 1.5$)$ & 0.001 & $57(52)$ & $3.6(2.8$ to 4.4$)$ & $<0.0001$ \\
\hline & No & $234(56)$ & & & $16(18)$ & & \\
\hline Attending school & Yes & $55(31)$ & $0.34(0.28$ to 0.4$)$ & $<0.0001$ & $60(35)$ & $0.26(0.2$ to 0.33$)$ & $<0.0001$ \\
\hline & No & $266(58)$ & & & $38(38)$ & & \\
\hline Working $>10 \mathrm{~h} /$ day & Yes & $142(62)$ & 1.7 (1.5 to 1.9$)$ & $<0.0001$ & $39(56)$ & 1.2 (1.1 to 1.5$)$ & 0.02 \\
\hline & No & $138(37)$ & & & $34(48)$ & & \\
\hline Punished for misdemeanours* & Yes & $135(78)$ & $3.6(3.2$ to 4.0$)$ & $<0.0001$ & NA & & \\
\hline & No & $145(29)$ & & & & & \\
\hline Self-reported health & Fair/poor & $210(60)$ & $1.4(1.1$ to 1.6$)$ & $<0.0001$ & $21(58)$ & 1.8 (1.4 to 2.2$)$ & $<0.0001$ \\
\hline Adult support & Yes & $108(28)$ & $0.32(0.25$ to 0.3$)$ & $<0.0001$ & $25(18)$ & 0.22 (0.11 to 0.34$)$ & $<0.0001$ \\
\hline & No & $172(64)$ & & & $48(80)$ & & \\
\hline Attends community centre & Yes & $160(57)$ & 0.71 (0.61 to 0.82 ) & $<0.0001$ & $40(32)$ & $0.66(0.51$ to 0.8$)$ & 0.006 \\
\hline & No & $120(68)$ & & & $33(46)$ & & \\
\hline
\end{tabular}

\footnotetext{
*Beating, food deprivation.
}

CDW, child domestic worker.

India but not in the Philippines. It has been generally assumed that younger children suffer more from the adverse effects of all types of work due to their immaturity and lack of experience, ${ }^{24}$ and much national legislation concerns age restrictions for work. But where conditions are good and children can attend school, maybe this is not the case. Living-in was associated with poorer psychosocial outcomes in the Philippines, but not in India, although only $12 \%$ were living with employers in India, making generalisations difficult. Living-in has been thought of as higher risk, since it usually means less social contact. ${ }^{17}$ But in some cases living conditions and health are better in the employer's home than in the child's own home, sometimes simply because in a city food and health facilities are more easily accessed. A study from Senegal found that CDWs who had migrated from rural areas had better health and nutritional status than non-migrants, concluding that they were better fed and cared for in domestic service than at home. ${ }^{18}$ CDWs in Guatemala cited excessive workloads and long hours of unpaid work as reasons for leaving their rural homes to migrate to cities for paid domestic work. ${ }^{19}$

There are clear policy implications. The diversity of working and living contexts and psychosocial outcomes shown in just two countries suggests that classifying child domestic work as a 'worst form of child labour' is inappropriate. Enforcement of such a classification would mean that governments would have to take steps to remove children from domestic work, which would not only be impossible to enforce but would also be counterproductive, with the risk that these child workers would be driven further underground, making it more difficult to protect the most vulnerable children, or forced into worse forms of employment. ${ }^{4}$ Moreover, this would be hugely problematic to implement given the acceptance of child domestic work in many societies.

However, this study shows that it is not domestic work that is intrinsically harmful but rather the circumstances and conditions of work in the employer's home, in the family and in society, and much of this could be ameliorated through regulatory measures. Employers should not employ younger children, should allow their employees to attend school, should limit hours of work, allow time off to attend community groups, socialise with peers and visit family, and should be informed that correction or teaching should be used rather than punishment. These points should be included in a contract agreed with the CDW employer. ${ }^{20}$ Even simple education of employers about good practice could be beneficial. Any attempts at regulation and legislation are complicated by the fact that the place of work is a private home. For this reason regulation needs to be accompanied by a local strategy for enforcement. As long as there are huge inequalities in many societies child domestic work will persist. The most important measures in the short term should aim to reduce the potential harm and promote good practice.

Contributors All authors contributed to the study design and conduct of the study. $\mathrm{TH}$ and $\mathrm{MO}$ conducted the analysis. All authors commented on drafts of the paper.

Acknowledgements The authors would like to thank the field staff who collected the data and the children who participated.

Funding This study was funded through a grant from the UK Department for International Development (DfID).

Competing interests None.

Ethics approval The ethics committee of UCL and of the local organisations approved this study.

Provenance and peer review Not commissioned; externally peer reviewed.

\section{REFERENCES}

1. Anti-Slavery International (ASI 2010). Child Domestic Work. http://www. antislavery.org (accessed 5 January 2012)

2. Blagbrough J. Child Domestic Labour: A Modern Form of Slavery. Children \& Society 2008;22:179-90.

3. Blagbrough J, Glynn E. Child Domestic Workers: Characteristics of the modern slave and approaches to ending such exploitation. Childhood 1999;6:51-6. 
4. Bourdillon M. Children as Domestic Employees: Problems and promises Journal of Children and Poverty 2009;15:1-18.

5. Estacio EV, Marks DF. Child labour and the International Labour Organization's Convention 182: a critical perspective. J Health Psychol 2005;10:475-84.

6. Banerjee SR, Bharati P, Vasulu TS, et al. Whole time domestic child labor in metropolitan city of Kolkata. Indian Pediatr 2008;45:579-82.

7. Human Rights Watch. Workers in the shadows: Abuse and Exploitation of child domestic workers in Indonesia, 2009. http://www.hrw.org (accessed 5 May 2012).

8. ILO-IPEC. Helping hands or shackled lives? Understanding child domestic labour and responses to it. Geneva Switzerland: ILO, 2004.

9. Black M. Child Domestic Workers: A Handbook on Good Practice in Programme Interventions. London: Anti-Slavery International, 2005.

10. Woodhead M. Combating child labour: listen to what the children say. Childhood 1999:6:27-49.

11. Erin-Brewer $\mathbf{S}$. Instrument for assessing the psychological effects of child domestic work. Anti Slavery International Working Document, 2003

12. Woodhead M. Psychosocial Impacts of Child Work: A Framework for Research, Monitoring and Intervention. Rome: Understanding Children's Work. Working Paper, 2004.

13. Camacho AZV. Family, child labour and migration: child domestic workers in metro Manila. Childhood 1999:6:57-73.
14. Camacho AZV. Children and Migration. Understanding the migration experiences of child domestic workers in the Philippines. In: Liebel M, Lutz R, eds. Sozialarbeit des Sudens Band 3 - Kindheiten und Kinderrechte. Olderburg: Paulo Freire Verlag, 2010:127-60.

15. Post D. Education and the child labour paradox today. Comp Educ Rev 2001;45: 127-39

16. Munene I, Ruto SJ. The right to education for children in domestic labour: empirical evidence from Kenya. Int Rev Educ 2010;56:127-47.

17. Jacquemin M. Can the language of rights get hold of the complex realities of child domestic work? The case of young domestic workers in Abidjan, Ivory Coast. Childhood 2006:13:389-406.

18. Garnier D, Bénéfice E. Habitual physical activity of Senegalese adolescent girls under different working conditions, as assessed by a questionnaire and movement registration. Ann Hum Biol 2001;28:79-97.

19. Aragao-Lagergren. A Urban Informal Sector. The case of Child Domestic Work in Guatemala City. Revista da Faculdade de Letras-Geografia 2003;XIX:99-109.

20. Klocker N. Negotiating Change: working with children and their employers to transform child domestic work in Iringa, Tanzania. Children's Geographies 2011; 9:205-20 